\title{
Monetary policy regimes and the forward bias for foreign exchange *
}

\author{
Juan A. Lafuente \\ University Jaume I, Department of Finance and Accounting, \\ 12071 Castellón (SPAIN), e-mail: lafuen@cofin.uji.es \\ Rafaela Perez \\ University Complutense, Department of Economic Analysis I \\ Campus de Somosaguas, 28223, Madrid (SPAIN) \\ e-mail: rmperezs@ccee.ucm.es \\ Jesús Ruiz ${ }^{\dagger}$ \\ University Complutense, Department of Quantitative Economics \\ Campus de Somosaguas, 28223, Madrid (SPAIN) \\ e-mail: jruinzand@ccee.ucm.es
}

February 5, 2016

\begin{abstract}
This paper provides a theoretical discussion of the forward premium anomaly. We reformulate the well-known Lucas (1982) model by allowing for the existence of monetary policy regimes. The monetary supply is viewed as having two stochastic components: a) a persistent component that reflects the preferences of the central bank regarding the long-run money supply or inflation target, and b) a transitory component that represents short-lived interventions. To generate agents' forecasts, we consider two scenarios: a) consumers can distinguish the permanent and the transitory components of the money supply (complete information), and b) consumers face a signal-extraction problem to disentangle permanent and transitory components of the money supply (incomplete information). We simulate the model from a careful estimate of the parameters involved
\end{abstract}

${ }^{*}$ The authors wish to thank O. Jordà, A.M. Taylor, A. Novales, seminar participants at UC Davis, XVII Finance Forum and the 4th CSDA International Conference on Computational and Financial Econometrics for helpful comments and suggestions. Financial support from the Spanish Ministry of Education through the ECO2012-31941 grant, the Fundación Ramon Areces through its program of economics research grants, the Valencian Regional Government through the PrometeoII/2013/015 grant and the University Jaume I through the P1.1A201209 grant is gratefully acknowledged. The usual disclaimer applies.

${ }^{\dagger}$ Corresponding author 
in the model. Numerical simulations reveal that, under complete information, forward unbiasedness cannot be rejected at conventionally significant levels. However, when learning about monetary policy is incorporated, the forward bias can be reproduced without artificially assuming an unreasonable degree of risk aversion.

Key words: monetary policy, regime shifts, learning, forward bias.

JEL classification: E43;F31;G14.

\section{Introduction}

Under risk neutrality and rational expectations, the forward exchange rate should be and unbiased predictor of the future spot rate. However, there is overwhelming empirical evidence in the literature rejecting the unbiasedness hypothesis (see, for example, the survey of Engel (1996)). Not only is a downward bias detected, the difference between the forward and spot exchange is also negatively correlated with future changes in spot rates, a pattern known as the forward premium puzzle. From the perspective of dynamic general equilibrium theory, although a substantial number of studies have addressed the ability of general equilibrium models building on Lucas (1982), to explain the forward premium puzzle they either require unreasonable risk aversion parameters or incredibly volatile consumption processes, even introducing external habit preferences over consumption. The recent work by Verdelhan (2010) provides additional insights using the Campbell and Cochrane (1999) approach but assuming that risk-free rates are low when consumption is close to the habit level. The model reproduces the uncovered interest parity (UIP) puzzle, but considers exogenous consumption processes, and its major concern is that simulated exchange rates are too volatile and too closely linked to consumption growth shocks.

This paper proposes a minor revision of the Lucas model that accounts for persistent deviations from the UIP condition. Our work is similar in spirit to Backus et el. (2010), but instead of abandoning explicit models of money in favor of interest rate rules, we model money supply exploiting the role of regime changes in financial markets ${ }^{1}$. The basic aspect is to reproduce the idea that exchange rates are characterized not only by highly persistent trends but also by abrupt changes arising infrequently ${ }^{2}$. While other papers try to explain the forward bias and the forward premium anomaly through habit persistence, recursive preferences and negative shocks to consumption growth, our attempt does not incorporate such aspects in order to assess the role of learning about monetary policy as a factor explaining the forward bias.

The monetary policy is specified as having two components (Andolfatto et al. 2004): one is determined in each time period by the prevailing monetary regime and reflects a particular target of the central bank regarding the money

\footnotetext{
${ }^{1}$ See Ang and Timmermann (2011), for a recent review of regime switching applications in finance.

${ }^{2}$ Baillie and Chang (2011) use a logistic smooth transition regression (LSTR) model and found that UIP is more likely to hold in a regime where volatility is unusually high.
} 
supply or inflation; the second represents short-lived interventions. Therefore our model departs from the Lucas model principally in that individuals can observe the historical sequence of money supply, but they cannot distinguish whether a monetary shock implies a regime shift or a transitory intervention. Economic agents consequently face a signal-extraction problem through a learning mechanism that allows monetary shocks to be broken down into estimated transitory and permanent components. ${ }^{3}$

Our main result is that when agents are capable of anticipating monetary policy shifts, that is, when they can exactly identify the transitory and persistent components of monetary disturbances, the forward unbiasedness hypothesis cannot be rejected at conventional significance levels. However, when agents need to solve a nontrivial signal extraction problem on the basis of the past history of monetary policy, a significant downward forward bias systematically appears. Also, as expected, high risk aversion intensifies the downward bias.

The remainder of the paper is structured as follows. Section 2 describes the theoretical model, while Section 3 describes how expectations are computed with complete and incomplete information. Section 4 discusses the implications of the model using estimated parameters from US and the EMU. Finally, Section 5 summarizes and provides concluding remarks.

\section{The Model}

Our modelling strategy is to extend the well-known Lucas (1982) model by allowing for the existence of regime changes in monetary policy. We will consider two scenarios: in the first one, structural parameters concerning the evolution of money supply over time are assumed to be known. By contrast, we also consider the more realistic case in which agents need to learn from current history in order to forecast future monetary policy. We start by presenting our version of Lucas' model and describing the assumed structure for monetary policy.

Let $X_{t}$ and $X_{t}^{*}$ denote the exogenous endowments of consumption goods in the domestic and foreign countries. Endowments are stochastic, and their natural logarithm follows an autoregressive process with normal innovations:

$$
\begin{aligned}
& X_{t}=\mu_{X_{t}} X_{t-1}, \\
& X_{t}^{*}=\mu_{X_{t}^{*}} X_{t-1}^{*},
\end{aligned}
$$

where:

\footnotetext{
${ }^{3}$ As Krugman (2007) said: "But Friedman never went there. His reality sense warned that [rational expectations] was taking the idea of Homo economicus too far". Chakraborty and Evans (2008) suggests that the learning theory approach to expectation formation in the foreign exchange markets should be considered a serious contender in future empirical work on the forward-premium puzzle. See also the recent works of Ilut (2010), Gourio et al. (2011) and Burnside et al. (2011) as representative recent papers that try to exploit the idea of learning about unobserved regimes in order to explain the forward premium anomaly. As to the role of monetary policy, Mark and Mohb (2007) propose a model where the forward premium anomaly is caused by unanticipated central bank interventions in the foreign exchange market.
} 


$$
\begin{aligned}
\left(\begin{array}{c}
\nabla \ln X_{t}-\ln \bar{\mu}_{X} \\
\nabla \ln X_{t}^{*}-\ln \bar{\mu}_{X^{*}}
\end{array}\right) & =\left(\begin{array}{cc}
\rho_{11} & \rho_{12} \\
\rho_{21} & \rho_{22}
\end{array}\right)\left(\begin{array}{c}
\nabla \ln X_{t-1}-\ln \bar{\mu}_{X} \\
\nabla \ln X_{t-1}^{*}-\ln \bar{\mu}_{X^{*}}
\end{array}\right)+\left(\begin{array}{c}
\xi_{X, t} \\
\xi_{X^{*}, t}
\end{array}\right), \\
\text { where, },\left(\begin{array}{c}
\xi_{X, t} \\
\xi_{X^{*}, t}
\end{array}\right) & \sim N\left(0_{2 \times 1},\left(\begin{array}{cc}
\sigma_{\xi_{X, t}}^{2} & \sigma_{\xi_{X, t} \xi_{X^{*}, t}} \\
\sigma_{\xi_{X^{*}, t}}^{2}
\end{array}\right)\right) .
\end{aligned}
$$

This way, similarly to Lafuente and Ruiz (2006), the potential correlation between real shocks in the domestic and foreign countries is explicitly taken into account. Let $\rho_{\xi_{X}, \xi_{X^{*}}}$ denote the linear correlation coefficient between these two shocks.

\subsection{The consumer's problem}

The optimization problem for the home consumer is:

$$
\begin{aligned}
& \operatorname{Max} \quad E_{0} \sum_{t=0}^{\infty} \beta^{t} \frac{1}{1-\gamma}\left[\left[\phi\left(C_{D, t}\right)^{\epsilon}+(1-\phi)\left(C_{F, t}\right)^{\epsilon}\right]^{(1-\gamma) / \epsilon}-1\right] \\
& \left\{C_{D, t}, C_{F, t}\right\} \\
& \text { s.t. } \\
& \begin{array}{c}
P_{D, t} C_{D, t}+S_{t} P_{F, t} C_{F, t} \leq Y_{t}, \\
Y_{t}=M_{t}+T_{t-1} \frac{S_{t}-F_{t-1}}{F_{t-1}},
\end{array}
\end{aligned}
$$

where $C_{D, t}$ and $C_{F, t}$ are the consumption levels of domestic and foreign goods at time $t, \gamma>0$ is the relative risk aversion coefficient, $\frac{1}{1-\epsilon}$ is the elasticity of substitution with $\epsilon<1$, while parameter $\phi \in(0,1)$ represents the weight of each consumption good in the utility function ${ }^{4}$. As for the budget constraint, $P_{D, t}$ and $P_{F, t}$ denote the prices of domestic and foreign goods at time $t, Y_{t}$ is the total income in period $t, S_{t}$ is the spot exchange rate, $F_{t-1}$ is the price of forward contract, $T_{t-1}$ is the respective amount of its currency that the home country sold forward in the previous period. The money supply $\left(M_{t}\right)$ plus the profits on each forward currency trade in period $t$ equals total home income. A similar optimization problem is solved by the foreign consumer:

$$
\begin{aligned}
& \operatorname{Max} E_{0} \sum_{t=0}^{\infty} \beta^{t} \frac{1}{1-\gamma}\left[\left[\phi\left(C_{D, t}^{*}\right)^{\epsilon}+(1-\phi)\left(C_{F, t}^{*}\right)^{\epsilon}\right]^{(1-\gamma) / \epsilon}-1\right](5) \\
& \left\{C_{D, t}^{*}, C_{F, t}^{*}\right\} \\
& \text { s.t. }
\end{aligned}
$$

\footnotetext{
${ }^{4}$ The effect on the foreign exchange from shocks to equations (1) and (2) could depend on the type of preferences of the representative agent. The asset pricing literature shows that time-additive utility as in the paper generates counterfactual results, increasing asset prices when expected growth decreases. The inclusion of recursive preference resolves this issue (Bansal and Yaron, 2004) and could improve the ability of the model to reproduce the forward bias.
} 


$$
\begin{gathered}
P_{D, t} C_{D, t}^{*}+S_{t} P_{F, t} C_{F, t}^{*} \leq Y_{t}^{*} S_{t}, \\
Y_{t}^{*}=M_{t}^{*}+T_{t-1}^{*} \frac{S_{t}-F_{t-1}}{F_{t-1} S_{t}} .
\end{gathered}
$$

\subsection{Optimum good choices.}

In any period $t$ the home consumer chooses levels of $C_{D, t}$ and $C_{F, t}$ that solves (4). First order conditions for choice of $C_{D, t}$ and $C_{F, t}$ are:

$$
\begin{gathered}
{\left[\phi\left(C_{D, t}\right)^{\epsilon}+(1-\phi)\left(C_{F, t}\right)^{\epsilon}\right]^{\frac{1-\gamma}{\epsilon}-1}\left(C_{D, t}\right)^{\epsilon-1}-\lambda_{t} P_{D, t}=0,} \\
{\left[\phi\left(C_{D, t}\right)^{\epsilon}+(1-\phi)\left(C_{F, t}\right)^{\epsilon}\right]^{\frac{1-\gamma}{\epsilon}-1}\left(C_{F, t}\right)^{\epsilon-1}-\lambda_{t} S_{t} P_{F, t}=0,} \\
Y_{t}-P_{D, t} C_{D, t}-P_{F, t} S_{t} C_{F, t}=0,
\end{gathered}
$$

where $\lambda_{t}$ denotes the Lagrange multiplier. From equations (6) and (7), we obtain:

$$
C_{F, t}=\left[\frac{(1-\phi) P_{D, t}}{\phi P_{F, t} S_{t}}\right]^{\sigma} C_{D, t},
$$

where $\sigma=\frac{1}{1-\epsilon}$ denotes the elasticity of substitution. Using (8) and the budget constraint, the demand function for the domestic and foreign good is as follows:

$$
\begin{gathered}
C_{D, t}=\frac{Y_{t} P_{D, t}^{-\sigma}}{P_{D, t}^{1-\sigma}+\left(\frac{1-\phi}{\phi}\right)^{\sigma}\left(S_{t} P_{F, t}\right)^{1-\sigma}}, \\
C_{F, t}=\left[\frac{(1-\phi) P_{D, t}}{\phi P_{F, t} S_{t}}\right]^{\sigma} \frac{Y_{t} P_{D, t}^{-\sigma}}{P_{D, t}^{1-\sigma}+\left(\frac{1-\phi}{\phi}\right)^{\sigma}\left(S_{t} P_{F, t}\right)^{1-\sigma}} .
\end{gathered}
$$

Using a similar procedure, the demands for the foreign country can be found, that is:

$$
\begin{gathered}
C_{F, t}^{*}=\left[\frac{(1-\phi) P_{D, t}}{\phi P_{F, t} S_{t}}\right]^{\sigma} C_{D, t}^{*}, \\
C_{D, t}^{*}=\frac{Y_{t}^{*} S_{t} P_{D, t}^{-\sigma}}{P_{D, t}^{1-\sigma}+\left(\frac{1-\phi}{\phi}\right)^{\sigma}\left(S_{t} P_{F, t}\right)^{1-\sigma}}, \\
C_{F, t}^{*}=\left[\frac{(1-\phi) P_{D, t}}{\phi P_{F, t} S_{t}}\right]^{\sigma} \frac{Y_{t}^{*} S_{t} P_{D, t}^{-\sigma}}{P_{D, t}^{1-\sigma}+\left(\frac{1-\phi}{\phi}\right)^{\sigma}\left(S_{t} P_{F, t}\right)^{1-\sigma}} .
\end{gathered}
$$




\subsection{Forward Contracting}

As well as the allocation of current resources between the two goods, the home consumer chooses the level of forward contracting in period $t$. The Euler condition is:

$$
E_{t}\left[\lambda_{t+1} \beta^{t+1}\left(\frac{S_{t+1}-F_{t}}{F_{t}}\right)\right]=0
$$

where $E_{t}$ denotes the conditional expectation based on the information set available in period $t$. From (15):

$$
E_{t}\left[\lambda_{t+1} S_{t+1}\right]=F_{t} E_{t} \lambda_{t+1}
$$

and taking into account (6), the value of the forward exchange rate at time $t$ consistent with the consumer's optimal choice is:

$$
F_{t}=\frac{E_{t}\left[\frac{\partial U_{t+1}}{\partial C_{F, t+1}} \frac{1}{P_{F, t+1}}\right]}{E_{t}\left[\frac{\partial U_{t+1}}{\partial C_{F, t+1}} \frac{1}{P_{F, t+1} S_{t+1}}\right]} .
$$

A similar expression applies for the foreign country:

$$
F_{t}=\frac{E_{t}\left[\frac{\partial U_{t+1}^{*}}{\partial C_{F, t+1}^{*}} \frac{1}{P_{F, t+1}}\right]}{E_{t}\left[\frac{\partial U_{t+1}^{*}}{\partial C_{F, t+1}^{*}} \frac{1}{P_{F, t+1} S_{t+1}}\right]} .
$$

\subsection{Equilibrium in the Goods Market}

In equilibrium, the total endowment of the two goods must be equal to the consumption of each good in the two countries, that is:

$$
\begin{gathered}
C_{D, t}+C_{D, t}^{*}=X_{D, t}, \\
C_{F, t}+C_{F, t}^{*}=X_{F, t} .
\end{gathered}
$$

Equilibrium prices of the two goods depend on the home and foreign money supplies as well as on their endowment. Taking into account that a) money is worthless after each period and b) each country's good can only be purchased with that country's currency, the following cash-in-advance spending constraints must hold:

$$
\begin{aligned}
& P_{D, t} X_{D, t}=M_{t}, \\
& P_{F, t} X_{F, t}=M_{t}^{*} .
\end{aligned}
$$

Also, in equilibrium, the following relationship between home and foreign derivative positions holds:

$$
T_{t}=-T_{t}^{*}
$$




\subsection{Monetary policy}

Following Andolfatto et al. (2004), we assume that the money supply at the beginning of period $t$ comprises two stochastic components: one component which reflects the main regime which is determined by the long-run monetary policy target, and the second component being the short-run error made in control of monetary aggregates by the central bank. For the home country, we have:

$$
M_{t}=\mu_{M_{t}} M_{t-1}, \text { with } \ln \mu_{M_{t}}=\ln \bar{\mu}_{M}+z_{t}+u_{t},
$$

where $M_{t}$ denotes the home money supply, $\mu$ is the average rate of growth of the natural logarithm of the money supply, and $z_{t}$ and $u_{t}$ and denote the regime and transitory component, respectively. We also assume that the regime component of the monetary policy to remain constant for a relatively long time period and a new regime appears only occasionally. Thus, the time evolution of $z_{t}$ can be expressed as follows:

$$
z_{t}=\left\{\begin{array}{cc}
z_{t-1}, & \text { with probability } p \\
g_{t}, & \text { with probability } 1-p, \text { where } g_{t} \sim N\left(0, \sigma_{g}^{2}\right) .
\end{array}\right.
$$

Parameter $p$ reflects the expected duration of any given regime, or alternatively, the persistence of the regime. While a shift in the regime variable $z_{t}$ can be given a number of interpretations, it could correspond to changes in preferences of monetary authorities for the proper long-term rate of monetary expansion. Alternatively, it could be also interpreted as the appointment of a new central bank governor, whose preferences over inflation outcomes differ from those of their predecessor (Andolfatto et al., 2004). Given that $z_{t}$ could be interpreted as the long-run monetary guidelines of the central bank, it is expected that such persistence would be fairly high. Parameter $\sigma_{g}^{2}$ reflects the potential size of the regime shift. The transitory money growth component of the $u_{t}$ is assumed to follow a standard $\operatorname{AR}(1)$ specification:

$$
u_{t}=\delta u_{t-1}+a_{t},
$$

with $0<\delta \ll 1$ and $a_{t} \sim N\left(0, \sigma_{a}^{2}\right)$. The variable $u_{t}$ can be interpreted as the outcome of a monetary intervention in financial markets as a reaction to shocks occurring in the world economy. In a similar way, the dynamics of the monetary policy of the foreign country is described as follows:

$$
\begin{gathered}
M_{t}^{*}=\mu_{M_{t}^{*}} M_{t-1}^{*}, \text { with } \ln \mu_{M_{t}^{*}}=\ln \bar{\mu}_{M^{*}}+z_{t}^{*}+u_{t}^{*}, \\
z_{t}^{*}=\left\{\begin{array}{c}
z_{t-1}^{*}, \quad \text { with probability } p^{*} \\
g_{t}^{*}, \quad \text { with probability } 1-p^{*}, \text { where } g_{t}^{*} \sim N\left(0, \sigma_{g^{*}}^{2}\right) . \\
u_{t}^{*}=\delta^{*} u_{t-1}^{*}+a_{t}^{*}, 0<\delta \ll 1, a_{t} \sim N\left(0, \sigma_{a^{*}}^{2}\right)
\end{array}\right.
\end{gathered}
$$

Domestic and foreign monetary shocks on the transitory component ( $a_{t}$ and $\left.a_{t}^{*}\right)$ may be correlated, with correlation coefficient $\rho_{a a^{*}}$. 


\subsection{Spot exchange rates}

Using the budget constraints and equations (18) to (21), the analytical expression of the equilibrium spot rate is:

$$
S_{t}=\frac{1-\phi}{\phi}\left(\frac{X_{F, t}}{X_{D, t}}\right)^{\varepsilon} \frac{M_{t}}{M_{t}^{*}} .
$$

\section{Computing expectations and estimating para- meters}

To obtain simulated equilibrium time series for spot and forward exchange rates, there are two aspects of prior work that we need to deal with: a) the computing of expectations, and b).the estimation of parameter values related to our monetary policy specification.

\subsection{Expectations under complete and incomplete infor- mation}

Since we are trying to asses whether learning is an explaining factor for the forward bias in our model, we consider two frameworks for generating expectations concerning monetary policy. Firstly, let us assume that consumers in the economy know the structural parameters. From now on we will refer this case as "complete information". In this case, consumers are perfectly able to distinguish the transitory and persistent components of money supply. For example, in the home country agents forecast the future money supply according to the following expression:

$$
E_{t}\left(\ln \left(\frac{M_{t+1}}{M_{t}}\right)-\ln \bar{\mu}_{M}\right)=E_{t}\left(z_{t+1}+u_{t+1}\right)=p z_{t}+\delta u_{t} .
$$

In the more realistic case of incomplete information, consumers are unable to determine exactly which policy regime applies at any given time, that is, they do not know how to break down historical realizations of money supply into permanent and transitory drivers. This implies that agents need to solve a signal extraction problem which determines how agents learn using the new information that arrives at the market to estimate any regime changes in monetary policy.

To compute expectations of $z_{t+1}$ and $u_{t+1}$ conditional to the information set available at time $t$ under incomplete information economic agents, that act as econometricians, use a state-space representation for the growth rate of the money supply mentioned above in a similar way as in Andolfatto et al. (2004). For example, in the case of the domestic country:

$$
y_{t+1}=H^{\prime} \xi_{t+1}
$$




$$
\xi_{t+1}=F \xi_{t}+\tilde{v}_{t+1}
$$

where:

$$
\begin{aligned}
& y_{t+1}=\ln \left(\frac{M_{t+1}}{M_{t}}\right)-\ln \bar{\mu}_{M}, \\
& \xi_{t}=\left(z_{t}, u_{t}\right)^{\prime}, \\
& \tilde{v}_{t}=\left(N_{t}, a_{t}\right), \text { where } N_{t}=\left\{\begin{array}{c}
(1-p) z_{t}, \text { with probability } p \\
g_{t}, \text { with probability } 1-p
\end{array}\right. \\
& F=\left(\begin{array}{cc}
p & 0 \\
0 & \delta
\end{array}\right), \\
& H^{\prime}=(1,1) .
\end{aligned}
$$

However, the use of the Kalman filter for the foregoing state-space representation is non-optimal because the noise vector $\tilde{v}_{t}$ is not Gaussian. To overcome the absence of normality we use an alternative state-space representation that is equivalent in mean and variance to the representation considered in Andolfatto et al. $(2004)^{5}$. For example, for the domestic country we have:

$$
\begin{gathered}
y_{t+1}=H^{\prime} \xi_{t+1} \\
\xi_{t+1}=F \xi_{t}+G_{R_{t+1}} E_{t} \xi_{t+1}+\Phi_{R_{t+1}} v_{t+1}
\end{gathered}
$$

where:

$$
\begin{aligned}
& y_{t+1}=\ln \left(\frac{M_{t+1}}{M_{t}}\right)-\ln \bar{\mu}_{M}, \\
& \xi_{t}=\left(z_{t}, u_{t}\right)^{\prime}, \\
& v_{t+1}=\left(g_{t+1}, a_{t+1}\right), \\
& F=\left(\begin{array}{cc}
\varphi & 0 \\
0 & \delta
\end{array}\right),|\varphi| \in(0,1) \\
& H^{\prime}=(1,1) \\
& G_{S_{t+1}}=\left(\begin{array}{cc}
\omega_{R_{t+1}} & 0 \\
0 & 0
\end{array}\right), \omega_{S_{t+1}}=\left\{\begin{array}{c}
\frac{1-\varphi}{p}, \text { if } R_{t+1}=1, \text { with probability } p \\
\frac{-\varphi}{p}, \text { if } R_{t+1}=0, \text { with probability } 1-p \\
0, \text { if } R_{t+1}=1, \text { with probability } p \\
1, \text { if } R_{t+1}=0, \text { with probability } 1-p
\end{array},\right.
\end{aligned}
$$

where $R_{t+1}=1$ reflects no regime shift, that is, no change for the current monetary policy target. On the contrary $R_{t+1}=0$ corresponds to the case of changes in the policy target. Now the state equation requires the use of statecontingent matrices, and explicitly incorporates the role of economic agents' expectations in learning about monetary policy-making.

Our state-space representation is observationally equivalent to the specification considered in Andolfatto et al. (2004) from the perspective of conditional mean and yields the same conditional variance if $\varphi=1-\frac{p}{2}$. The proof of such statements can be found in Lafuente et al. (2011). Additionally, our representation has the advantage of having Gaussian innovations for the state equation,

\footnotetext{
${ }^{5}$ A detailed explanation of this alternative representation can be found in Lafuente et al. (2011).
} 
and therefore the Kalman filter becomes an optimal signal extraction procedure to disentangle $\hat{y}_{t+1 \mid t}$ as the sum of $\hat{z}_{t+1 \mid t}$ and $\hat{u}_{t+1 \mid t}$.

\subsection{Maximum likelihood estimation of parameters for mon- etary policy}

Interestingly enough, this representation allows us not only the optimal use of the Kalman filter as the signal extraction procedure to obtain $\hat{y}_{t+1 \mid t}$, but also to perform the maximum likelihood estimation of the parameters involved in the monetary policy.

To obtain the log-likelihood function in the case of the domestic country, first we compute the conditional density of $y_{t}$ to $Y_{t-1} \equiv\left(y_{1}, y_{2}, \ldots, y_{t-1}\right)^{\prime}$ and $R_{t}$ :

$$
f\left(y_{t} \mid Y_{t-1}, R_{t} ; \Theta\right)=(2 \pi)^{-\frac{1}{2}}\left|\Omega_{t}^{(k)}\right|^{-\frac{1}{2}} \exp \left(-\frac{1}{2} \hat{\mu}_{t}^{(k) \prime}\left(\Omega_{t}^{(k)}\right)^{-1} \hat{\mu}_{t}^{(k)}\right)
$$

where $\Omega_{t}^{(k)}=H^{\prime} P_{t \mid t-1}^{(k)} H, \hat{\mu}_{t}^{(k)}=y_{t}-H^{\prime} \hat{\xi}_{t \mid t-1}^{(k)}, \Theta=\left(\delta, p, \sigma_{g}, \sigma_{a}\right)^{\prime}, k=0,1$ denotes the two alternative contingent states, and $P_{t \mid t-1}^{(k)}=E\left[\left(\xi_{t}-\hat{\xi}_{t \mid t-1}^{(k)}\right)\left(\xi_{t}-\hat{\xi}_{t \mid t-1}^{(k)}\right)^{\prime}\right]$.

Second, we compute the marginal density function of $y_{t}$ conditional to $Y_{t-1}$ as follows:

$$
f\left(y_{t} \mid Y_{t-1} ; \Theta\right)=\sum_{k=0}^{1} f\left(y_{t} \mid Y_{t-1}, R_{t}=k ; \Theta\right) \times \operatorname{Pr}\left[R_{t}=k\right] .
$$

Finally, we obtain the parameters contained in $\Theta$ by solving the following optimization problem:

$$
\underset{\Theta}{\operatorname{Max}} \ln L(\Theta) \Leftrightarrow \underset{\Theta}{\operatorname{Max}} \sum_{t=1}^{T} \ln \left[f\left(y_{t} \mid Y_{t-1} ; \Theta\right)\right]
$$

A similar problem applies to the foreign country in estimating $\Theta^{*}=\left(\delta^{*}, p^{*}, \sigma_{g^{*}}, \sigma_{a^{*}}\right)$.

\section{Numerical results}

Table 1 summarizes the point estimates (standard deviations are in brackets) for all the relevant parameters involved in the monetary policy based on the maximum likelihood estimation procedure using the state-space representation that we mentioned at the end of the previous section. We used quarterly data of M2 for the US and the EMU covering the sample period from 1980:Q1 to 2011:Q1 and 1991:Q1 to 2011Q1, respectively. In our model the price of domestic and foreign goods, as well as the spot and forward exchange rates are endogenously determined, and therefore, we focus on the two largest economies in terms of nominal GDP to estimate monetary policy rule parameters. 
Once the transitory components are estimated, we can compute the correlation between the domestic and the foreign innovation that appear in the autoregressive processes concerning the persistent components of the monetary policy. In particular we obtain $\rho_{a a^{*}}=0.3188$.

Given that we are going to simulate quarterly data, we consider a discount factor of 0.99 , a commonly used value in the real business cycle literature. As to the weight of each consumption good in the utility function we set $\phi=0.5$. Given that we have no habit formation we initially depart from Campbell and Cochrane (1999) by setting a risk aversion parameter $\gamma=4$. We also use time series data to estimate the parameters involved in real endowment evolution over time. Using the common sample (1991:Q1 to 2011Q1), the estimation of the bivariate VAR for the growth rate of GDP leads to the following point estimates:

$$
\left(\begin{array}{c}
\nabla \ln X_{t}-\ln \bar{\mu}_{X} \\
\nabla \ln X_{t}^{*}-\ln \bar{\mu}_{X^{*}}
\end{array}\right)=\left(\begin{array}{cc}
0.5258 & -0.0521 \\
0.2883 & 0.3883
\end{array}\right)\left(\begin{array}{c}
\nabla \ln X_{t-1}-\ln \bar{\mu}_{X} \\
\nabla \ln X_{t-1}^{*}-\ln \bar{\mu}_{X^{*}}
\end{array}\right)+\left(\begin{array}{c}
\hat{\xi}_{X, t} \\
\hat{\xi}_{X^{*}, t}
\end{array}\right)
$$

with $\bar{\mu}_{X}=1.0063, \bar{\mu}_{X^{*}}=1.0040, \sigma_{\hat{\xi}_{X, t}}=.0060, \sigma_{\hat{\xi}_{X^{*}, t}}=.0059$ and the correlation between the home and foreign real shocks $\rho_{\xi_{X}, \xi_{X^{*}}}=0.1742$. Table 2 shows the baseline parameterization that we consider. We simulated the model 1,000 times generating observations for each time series with the same sample size of the largest dataset used in the estimation. Economic agents need to solve a signal-extraction problem for estimating the two individual components of the money supply. We assume that they face this problem by constructing an optimal forecast based on all the relevant information. Each simulation is performed under two scenarios: complete and incomplete information. The complete information scenario corresponds to the case when agents can perfectly identify permanent and transitory components of monetary policy. In contrast, under incomplete information, agents face a nontrivial signal extraction problem because they can observe only aggregated noise.

Solving the model requires the evaluation of highly non-linear expressions, precluding the possibility of an analytical solution. Appendix 1 provides a detailed explanation of the solution method proposed to obtain simulated equilibrium time series for spot and forward exchange rates. It should be highlighted that the simulation of the model economy under incomplete information requires the use of the Kalman filter to compute expectations for $z_{t}$ and $u_{t}$ as previously described in Section 3.

To test the unbiasedness of the forward exchange rate as a forecast of the future spot rate, following Fama (1984), the econometric specification most commonly used in the literature is the following:

$$
s_{t+k}-s_{t}=\alpha+\beta\left(f_{t+k}-s_{t}\right)+\xi_{t+k}
$$

where $s_{t+k}$ is the log of the nominal exchange rate in time $t+k, f_{t+k}$ is the log of the $k$-period forward rate traded at time $t$ and $\xi_{t+k}$ is a random error. 
To clearly identify the ability of the model to reproduce the forward bias we not only present the median estimate and the confidence interval at the $10 \%$ significance level, but also the density functions of the estimated slopes with the 1,000 regressions for each scenario (complete and incomplete information). Figure 1 summarizes the results obtained from the baseline parameterization. It can be observed that the existence of learning clearly produces a downward bias in the estimated slope coefficient. On the contrary, under rational expectations the estimated slope is close to one. Indeed we cannot reject the null hypothesis of $\beta=1$ against the alternative $\beta<1$ at the $10 \%$ significance level. However, under incomplete information the null is rejected.

The hypothesis of rational expectations would require that market participants be homogeneous in their formation of expectations. But this assumption implicitly assumes that agents do not make systematic errors when forecasting the relevant variables and parameters (for example the probability of regime shift). However neither complete information nor perfect foresight are features of financial markets. In order to give a better understanding of the economics of the underlying mechanism that leads to the forward bias, Figure 2 shows the price adjustment process under rational expectations and bounded rationality using the baseline parameterization. For a given realization of the stochastic component $z_{t}$ (the domestic persistent component of the monetary policy), the graph depicts the equilibrium spot rate as well as the corresponding equilibrium forward rates under complete and incomplete information. As expected, agents are slower to update their expectations of forward prices under incomplete information. As a consequence of these sticky expectations, during the transitional dynamics that takes place after the arising of a monetary shift, spot and forward prices could show a transitory negative correlation (see, for example, the time evolution around time periods 17 and 22). Remember that the OLS estimator for the slope in the Fama regression can be expressed as follows:

$$
\hat{\beta}_{O L S}=\beta\left(1+\frac{\operatorname{Cov}\left(f_{t+k}-s_{t}, \xi_{t+k}\right)}{\operatorname{Var}\left(f_{t+k}-s_{t}\right)}\right)
$$

and, therefore, the point estimate is below 1 under the null of $\beta=1$ (rational expectations) when spot and forward prices are negatively correlated. In sum, what the model shows is that, given that learning is time-consuming, the price discovery role of the forward market is not as expected under rational expectations.

To analyze the sensitivity of our results we also present numerical simulations by changing some parameters from the benchmark setting. In particular, we check the robustness of our results to changes in the curvature of the utility function (parameter $\gamma$ ) and the degree of substitutability (parameter $\epsilon$ ).

Figure 3 presents the results with lower risk aversion, in particular for $\gamma=1.5$. As is apparent, the nature of our results from the baseline parameterization remains qualitatively unchanged. As expected, the downward bias is now smaller. When risk aversion is lower the impact of consumption shocks on the change in marginal utility is smaller. Under such conditions agents pre- 
fer less persistent consumption, which leads to lower persistence in the forward premium and a shorter time period with negative correlations between spot and forward prices during the transitional dynamics.

Figure 4 shows the results with $\epsilon=0.5$, that is, considering a higher degree of substitution between domestic and foreign goods. Again, the distribution of the slope coefficient under complete information departs from the one corresponding to the case of incomplete information. Similarly to the baseline scenario, the null hypothesis of $\beta=1$ against the alternative of $\beta<1$ cannot be rejected at the $10 \%$ significance level under complete information. However, it is rejected when learning takes place. The intuition is that a higher degree of substitution tends to produce a more asymmetric consumption basket, and when the relative weight of the foreign good is relatively more important the exposure to exchange risk increases dramatically. As a consequence, the forward discount becomes more persistent and the downward bias increases.

To reinforce the idea that learning about monetary policy plays a key role we finally simulate the model with a new scenario where uncertainty about monetary policy making is clearly higher in the domestic country (i.e. higher probability of regime shift and higher volatility for the persistent and transitory shocks). The rest of the parameters in both countries take benchmark values. Figure 5 shows the results. Compared with the baseline scenario, the downward bias in the slope coefficient tends to increase. When monetary policy is implemented in a non-similar way, learning about shifts is harder, and the updating process for expectations is much slower. This result is consistent with those reported in Sakoulis et al. (2010), who find that structural breaks in the forward discount process as a consequence of changes in monetary policy objectives of the central banks of different countries lead to a significant downward bias for the forward discount coefficient in the Fama regression.

\section{Concluding remarks}

This paper has explored an explanation for the forward bias in foreign exchange markets based on a stochastic and dynamic general equilibrium model that incorporates regime shifts in monetary policy. Based on the well-known Lucas' model, its main innovation lies in the existence of a representative agent that needs to estimate the current state of monetary policy from analyzing the past history. The money supply is viewed as having two stochastic components: a) a persistent component that reflects the preferences of the central bank regarding the long-run money supply or inflation target, and b) a transitory component that represents short-lived interventions or errors in controlling the money supply. In addition, the model is formulated to allow for different weights for each consumption good in the utility function and the possibility that home and foreign real shocks as well as transitory monetary shocks in the two countries may be correlated.

We present results from numerical simulations focusing on the role of monetary policy. In particular, we consider two scenarios: a) complete information, 
with consumers that can perfectly distinguish the transitory and persistent components of money supply, and b) incomplete information, where consumers are unable to perfectly determine which policy regime applies at any given time, and face a signal-extraction problem.

We simulated the model initially using a baseline parameterization which is based on a careful estimation from quarterly data for the US and the EU. Numerical simulations suggest that the need for learning is a factor explaining the forward bias. While under incomplete information the forward discount still points in the right direction, a significant downward bias arises in comparison with the scenario of complete information, where the null hypothesis of unitary slope cannot be rejected at conventional significant levels. A combination of our monetary uncertainty with habit persistence could reproduce the anomaly. We left this issue for further research.

\section{References}

[1] Andolfatto, D., Hendry, S. and K. Moran (2004), Labour markets, liquidity and monetary policy regimes, Canadian Journal of Economics 37, 392-420.

[2] Ang A. and A. Timmermann, (2011), Regime changes and financial markets, Netspar Discussion Papers, DP 06/2011-068

[3] Backus, D., F. Gavazzoni, C. Telmer and S. E. Zin (2010), Monetary policy and the uncovered interest rate puzzle, NBER Working Paper 16218.

[4] Baillie R.T. and S.S. Chang (2011), Carry trades, momentum tradind and the forward premium anomaly, Journal of Financial Markets 14, 441-464.

[5] Bansal, R. and A. Yaron (2007), Risks for the Long Run: A Potential Resolution of Asset Pricing Puzzles, The Journal of Finance 59, 1481-1509.

[6] Burnside A.C., B. Han, D. Hirshleifer and T.Y. Wang (2011), Investor overconfidence and the forward premium puzzle, Review of Economic Studies, $78(2), 523-558$

[7] Campbell J.Y. and J.H. Cochrane (1999), By force of habit: a consumptionbased explanation of aggregate stock market behaviour, Journal of Political Economy 107, 205-251.

[8] Chakraborty A and G W. Evans (2008), Can perpetual learning explain the forward-premium puzzle?, Journal of Monetary Economics 55, 470-490.

[9] Engle, C. (1996), The forward discount anomaly and the risk premium: A survey of recent evidence, Journal of Empirical Finance 3, 123-192.

[10] Fama, E.F. (1984), Forward and spot exchange rates, Journal of Monetary Economics 14, 319-338. 
[11] Gourio, F., M. Siemer and A. Verdelhan (2011), International risk cycles, Working Paper 17277 NBER, August 2011.

[12] Ilut, C.L. (2010), Ambiguity aversion: Implications for the Uncovered Interest Rate Parity puzzle, Working Papers 10-53, Duke University, Department of Economics.

[13] Krugman, P. (2007), Who was Milton Friedman, The New York Review of Books, 54(2).

[14] Lafuente, J.A. and J. Ruiz, (2006), Monetary policy and forward bias for foreign exchange revisited: Empirical evidence from the US-UK exchange rate, Economic Modelling 23, 238-264.

[15] Lafuente, J.A., Pérez R. and J. Ruiz (2011), Estimating persistent and transitory monetary shocks: implications for monetary policy, Working paper 31, Business Economic Series 08, Universidad Carlos III de Madrid.

[16] Lucas, R. (1982), Interest rates and currency prices in a two-country world, Journal of Monetary Economics 10, 335-59.

[17] Mark, C.M. and Y. Mohb (2007), Official interventions and the forward premium anomaly, Journal of Empirical Finance, 14, 499-522

[18] Sakoulis, G., Zivot, E. and K. Choi (2010), Structural change in the forward discount: Implications for the forward rate, Journal of Empirical Finance 17, 957-966.

[19] Verdelhan, A. (2010), A Habit-based Explanation of the Exchange Rate Risk Premium, Journal of Finance 65, 123-146. 


\section{Appendix 1}

This appendix contains the explanation of the solution method used. From the optimality conditions, we obtain the following set of equations:

$$
\begin{aligned}
& S_{t}=\frac{1-\phi}{\phi}\left(\frac{X_{F, t}}{X_{D, t}}\right)^{\varepsilon} \frac{M_{t}}{M_{t}^{*}} \\
& P_{D, t}=\frac{M_{t}}{X_{D, t}} \\
& P_{F, t}=\frac{M_{t}^{*}}{X_{F, t}} \\
& C_{F, t}=\left[\frac{(1-\phi) P_{D, t}}{\phi P_{F, t} S_{t}}\right]^{\sigma} C_{D, t} \\
& C_{F, t}^{*}=\left[\frac{(1-\phi) P_{D, t}}{\phi P_{F, t} S_{t}}\right]^{\sigma} C_{D, t}^{*} \\
& C_{F, t}=\left[\frac{(1-\phi) P_{D, t}}{\phi P_{F, t} S_{t}}\right]^{\sigma} \frac{\left[M_{t}+T_{t-1}\left(\frac{S_{t}-F_{t-1}}{F_{t-q}}\right) P_{D, t}^{-\sigma}\right]}{P_{D, t}^{1-\sigma}+\left(\frac{1-\phi}{\phi}\right)^{\sigma}\left(S_{t} P_{F, t}\right)^{1-\sigma}} \\
& C_{F, t}^{*}=\left[\frac{(1-\phi) P_{D, t}}{\phi P_{F, t} S_{t}}\right]^{\sigma} \frac{\left[M_{t}^{*}+T_{t-1}^{*}\left(\frac{S_{t}-F_{t-1}}{F_{t-q}}\right) S_{t} P_{D, t}^{-\sigma}\right]}{P_{D, t}^{1-\sigma}+\left(\frac{1-\phi}{\phi}\right)^{\sigma}\left(S_{t} P_{F, t}\right)^{1-\sigma}} \\
& T_{t-1}^{*}=T_{t-1} \\
& F_{t}=\frac{E_{t}\left[C_{D, t+1}^{\epsilon-1}\left(\phi C_{D, t+1}^{\epsilon}+(1-\phi) C_{F, t+1}^{\epsilon}\right)^{\frac{1-\gamma}{\epsilon}-1} \frac{S_{t+1}}{P_{D, t+1}}\right]}{E_{t}\left[C_{D, t+1}^{\epsilon-1}\left(\phi C_{D, t+1}^{\epsilon}+(1-\phi) C_{F, t+1}^{\epsilon}\right)^{\frac{1-\gamma}{\epsilon}-1} \frac{1}{P_{D, t+1}}\right]} \\
& F_{t}=\frac{E_{t}\left[\left(C_{F, t+1}^{*}\right)^{\epsilon-1}\left(\phi\left(C_{D, t+1}^{*}\right)^{\epsilon}+(1-\phi)\left(C_{F, t+1}^{*}\right)^{\epsilon}\right)^{\frac{1-\gamma}{\epsilon}-1} \frac{1}{P_{F, t+1}}\right]}{E_{t}\left[\left(C_{F, t+1}^{*}\right)^{\epsilon-1}\left(\phi\left(C_{D, t+1}^{*}\right)^{\epsilon}+(1-\phi)\left(C_{F, t+1}^{*}\right)^{\epsilon}\right)^{\frac{1-\gamma}{\epsilon}-1} \frac{1}{\frac{S_{t+1} P_{F, t+1}}{}}\right]}
\end{aligned}
$$

Using equations (A1) to (A8), equations (A9) and (A10) can be expressed as follows:

$$
F_{t}=\frac{E_{t}\left[g_{1}\left(F_{t}, M_{t} ; M_{t+1}, M_{t+1}^{*}, X_{D, t+1}, X_{F, t+1}\right)\right]}{E_{t}\left[g_{2}\left(F_{t}, M_{t} ; M_{t+1}, M_{t+1}^{*}, X_{D, t+1}, X_{F, t+1}\right)\right]}
$$




$$
F_{t}=\frac{E_{t}\left[g_{3}\left(F_{t}, M_{t} ; M_{t+1}, M_{t+1}^{*}, X_{D, t+1}, X_{F, t+1}\right)\right]}{E_{t}\left[g_{4}\left(F_{t}, M_{t} ; M_{t+1}, M_{t+1}^{*}, X_{D, t+1}, X_{F, t+1}\right)\right]}
$$

where functions $g_{i}(\cdot), i=1,2,3,4$ are:

$$
\begin{gathered}
g_{1}=\Psi_{D}^{-\gamma}\left[\phi+(1-\phi)\left(\frac{X_{F, t+1}}{X_{D, t+1}}\right)^{(1-\epsilon) \sigma \epsilon}\right]^{\frac{1-\gamma}{\epsilon}-1}\left(\frac{X_{D, t+1}}{M_{t+1}}\right) \\
g_{2}=\Psi_{D}^{-\gamma}\left[\phi+(1-\phi)\left(\frac{X_{F, t+1}}{X_{D, t+1}}\right)^{(1-\epsilon) \sigma \epsilon}\right]^{\frac{1-\gamma}{\epsilon}-1} \times \\
\left(\frac{X_{D, t+1}}{M_{t+1}}\right) \frac{\phi}{1-\phi}\left(\frac{X_{D, t+1}}{X_{F, t+1}}\right)^{\frac{M_{t+1}^{*}}{M_{t+1}}} \\
g_{3}=\left(\frac{X_{F, t+1}}{X_{D, t+1}}\right)^{(1-\epsilon) \sigma(\epsilon-1)}\left(\frac{X_{F, t+1}}{M_{t+1}^{*}}\right) \times \\
g_{4}^{-\gamma}\left[\phi+(1-\phi)\left(\frac{X_{F, t+1}}{X_{D, t+1}}\right)^{(1-\epsilon) \sigma \epsilon}\right]^{\frac{1-\gamma}{\epsilon}-1} \\
\left(\frac{X_{F, t+1}}{X_{D, t+1}}\right)^{(1-\epsilon) \sigma(\epsilon-1)} \Psi_{F}^{-\gamma}\left[\phi+(1-\phi)\left(\frac{X_{F, t+1}}{X_{D, t+1}}\right)^{(1-\epsilon) \sigma \epsilon}\right]^{\frac{1-\gamma}{\epsilon}-1} \\
\left(\frac{X_{F, t+1}}{M_{t+1}}\right)^{\frac{\phi}{1-\phi}}\left(\frac{X_{D, t+1}}{X_{F, t+1}}\right)^{\epsilon}
\end{gathered}
$$

being:

$$
\begin{aligned}
& \Psi_{D}=\frac{M_{t+1}^{*}+T_{t}\left[\frac{\frac{1-\phi}{\phi}\left(\frac{X_{F, t+1}}{X_{D, t+1}}\right)^{\epsilon} \frac{M_{t+1}}{F_{t+1}^{*}}-F_{t}}{\left(\frac{M_{t+1}}{X_{D, t+1}}\right)^{-\sigma}+\left(\frac{1-\phi}{\phi}\right)^{\sigma}\left[\frac{1-\phi}{\phi}\left(\frac{X_{F, t+1}}{X_{D, t+1}}\right)^{\epsilon} \frac{M_{t+1}}{X_{D, t+1}}\right)^{-\sigma} M_{t+1}^{*} X_{F, t+1}^{*}}\right]^{1-\sigma}}{M_{t}} \\
& \Psi_{F}=\frac{M_{t+1}+T_{t}\left[\frac{\frac{1-\phi}{\phi}\left(\frac{X_{F, t+1}}{X_{D, t+1}}\right)^{\epsilon} \frac{M_{t+1}}{M_{t+1}^{*}}-F_{t}}{F_{t}}\right] \frac{1-\phi}{\phi}\left(\frac{X_{F, t+1}}{X_{D, t+1}}\right)^{\epsilon} \frac{M_{t+1}}{M_{t+1}^{*}}\left(\frac{M_{t+1}}{X_{D, t+1}}\right)^{-\sigma}}{\left(\frac{M_{t+1}}{X_{D, t+1}}\right)^{-\sigma}+\left(\frac{1-\phi}{\phi}\right)^{\sigma}\left[\frac{1-\phi}{\phi}\left(\frac{X_{F, t+1}}{X_{D, t+1}}\right)^{\epsilon} \frac{M_{t+1}}{M_{t+1}^{*}} \frac{M_{t+1}^{*}}{X_{F, t+1}}\right]^{1-\sigma}}
\end{aligned}
$$


We use linear and log-linear approximation of functions $g_{i}(\cdot), i=1,2,3,4$ around the estimated trend using the Hoddrick-Prescott filter for $X_{D, t+1}, X_{F, t+1}$, $M_{t+1}$ and $M_{t+1}^{*}$. Substituting such approximant functions into equations (A11) and (A12), we obtain a system of two equations with two variables $\left(F_{t}, T_{t}\right)$ as a function of the following expectations: $E_{t}\left(\ln \left(\mu_{X_{t+1}}\right)\right), E_{t}\left(\ln \left(\mu_{X_{t+1}^{*}}\right)\right)$, $E_{t}\left(\ln \left(\mu_{M_{t+1}}\right)\right), E_{t}\left(\ln \mu_{M_{t+1}^{*}}\right)$. Expectations for endowments are always computed as $E_{t}\left(\ln \left(\mu_{X_{t+1}}\right)\right)=\left(1-\rho_{X}\right) \ln \left(\bar{\mu}_{X}\right)+\rho_{11} \ln \left(\mu_{X_{t}}\right)+\rho_{12} \ln \left(\mu_{X_{t}^{*}}\right)$ and $E_{t}\left(\ln \left(\mu_{X_{t+1}^{*}}\right)\right)=\left(1-\rho_{X^{*}}\right) \ln \left(\bar{\mu}_{X^{*}}\right)+\rho_{21} \ln \left(\mu_{X_{t}}\right)+\rho_{22} \ln \left(\mu_{X_{t}^{*}}\right)$ for the domestic and the foreign country, respectively. However, for the monetary policy we consider two alternative scenarios:

a) Complete information: in this case, expectations are computed as follows: $\delta^{*} u_{t}^{*}$

$E_{t}\left(\ln \left(\mu_{M_{t+1}}\right)\right)=\ln \bar{\mu}_{M}+p z_{t}+\delta u_{t}$, and $E_{t}\left(\ln \left(\mu_{M_{t+1}^{*}}\right)\right)=\ln \bar{\mu}_{M^{*}}+p^{*} z_{t}^{*}+$

b) Incomplete information:

$E_{t}\left(\ln \left(\mu_{M_{t+1}}\right)-\ln \bar{\mu}_{M}\right)=\hat{y}_{t+1 \mid t}=\hat{z}_{t+1 \mid t}+\hat{u}_{t+1 \mid t}$, and $E_{t}\left(\ln \left(\mu_{M_{t+1}^{*}}\right)-\ln \bar{\mu}_{M^{*}}\right)=$ $\hat{y}_{t+1 \mid t}^{*}=\hat{z}_{t+1 \mid t}^{*}+\hat{u}_{t+1 \mid t}^{*}$ by applying the Kalman filter using equations (23) and (24).

Once the relevant expectations have been computed either under complete or incomplete information, the above system for $\left(F_{t}, T_{t}\right)$ can be solved. 
Appendix 2

Table 1. Point estimates for persistent and transitory components of the monetary policy

\begin{tabular}{l|llll}
\hline US & $p=.8695[.0674]$ & $\delta=.6103[0.0517]$ & $\sigma_{g}^{2}=.0128[0.0058]$ & $\sigma_{a}^{2}=.0048[0.0002]$ \\
\hline EMU & $p^{*}=.8528[0.0056]$ & $\delta^{*}=.7902[0.0647]$ & $\sigma_{g^{*}}^{2}=.0104[0.0044]$ & $\sigma_{a^{*}}^{2}=.0038[0.0001]$ \\
\hline
\end{tabular}

Table 2. Baseline parameterization

\begin{tabular}{llll}
\hline \multicolumn{3}{l}{ Home country (US) } & \multicolumn{3}{c}{ Foreign country (EMU) } \\
\hline$\rho_{11}$ & 0.5258 & $\rho_{22}$ & 0.3883 \\
$\rho_{12}$ & -0.0521 & $\rho_{21}$ & 0.2883 \\
$\bar{\mu}_{X}$ & 1.0063 & $\bar{\mu}_{X^{*}}$ & 1.0040 \\
$\sigma_{X}$ & 0.0060 & $\sigma_{X^{*}}$ & 0.0059 \\
$\sigma_{g}$ & 0.0128 & $\sigma_{g^{*}}$ & 0.0104 \\
$\sigma_{a}$ & 0.0048 & $\sigma_{a^{*}}$ & 0.0038 \\
$\delta$ & 0.6103 & $\delta^{*}$ & 0.7902 \\
Correlations: $\rho_{\xi_{X}}, \xi_{X^{*}}=0.1742 ; \rho_{a a^{*}}=0.4243$ \\
Parameter to control the elasticity of substitution: $\epsilon=-1$ \\
Discount factor: $\beta=0.99$ \\
Weight of each consumption good in the utility function: $\phi=0.50$ \\
Curvature of the utility function: $\gamma=4.0$ \\
Probability of regime shifts: $1-p=1-0.8695 ; 1-p^{*}=1-0.8528$ \\
\hline
\end{tabular}


Figure 1. Density functions of simulated slopes. Baseline parameterization

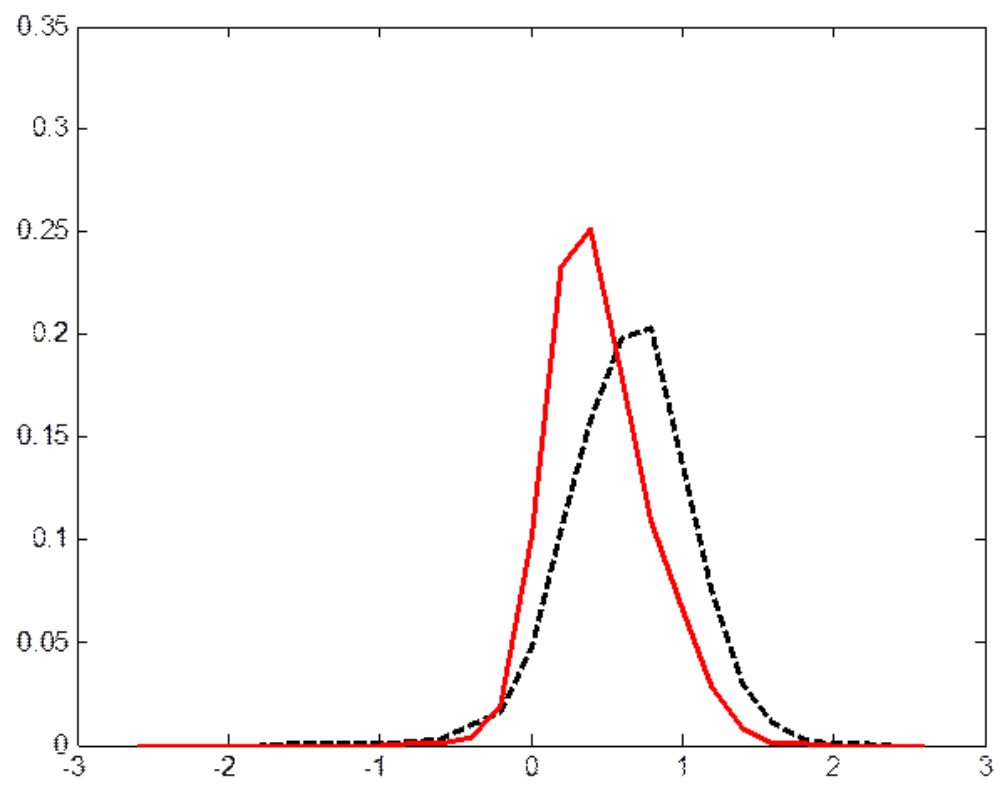

Note: the dotted line corresponds to complete information Median slope

Complete information 0.6636

Complete information 1.1408 Incomplete information 90-th quantile 0.4735 Incomplete information 0.9057 th-quantile that corresponds to the unitary value Complete information $82 \%$ Incomplete information $93 \%$ 
Figure 2 Adjustment of forward rates under rational expectations and bounded rationality

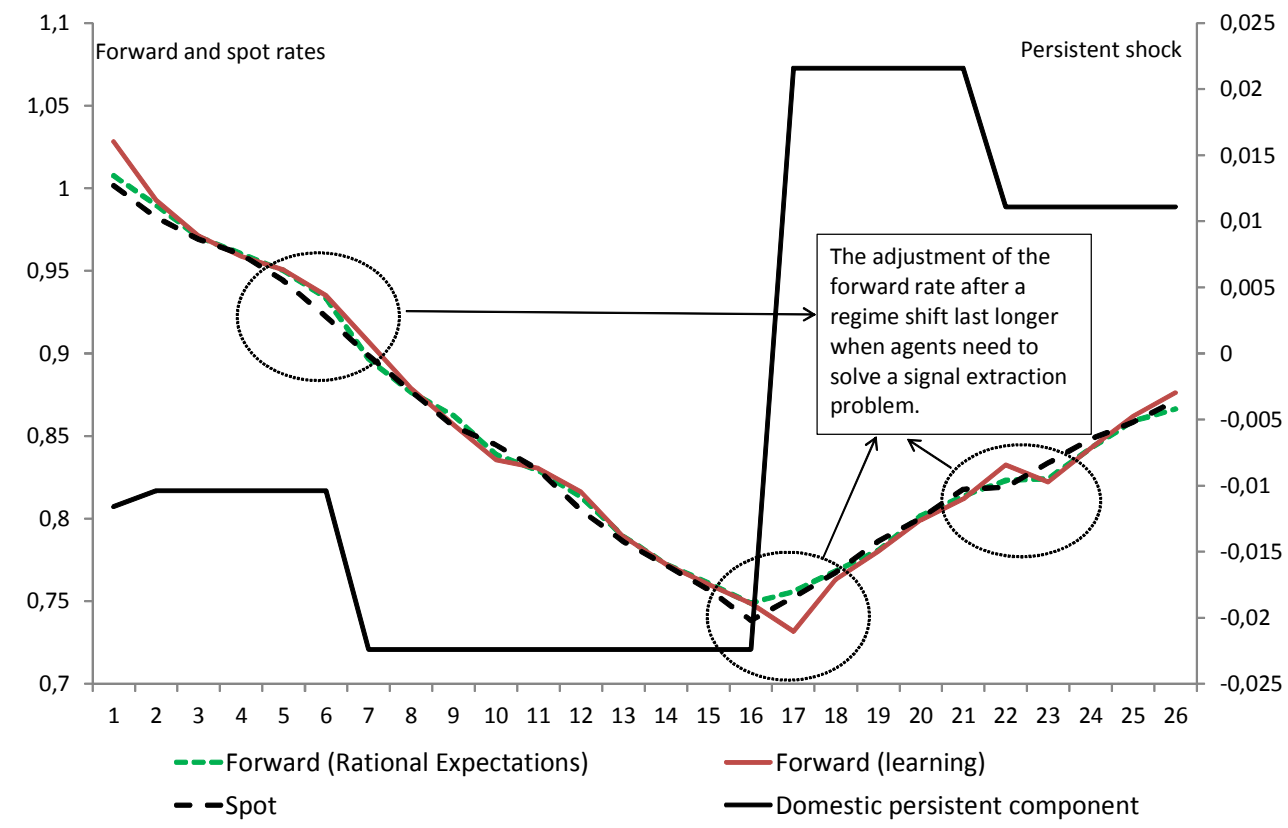


Figure 3. Density functions of simulated slopes. Sensitivity to parameter $\gamma$ $(\gamma=1.5)$

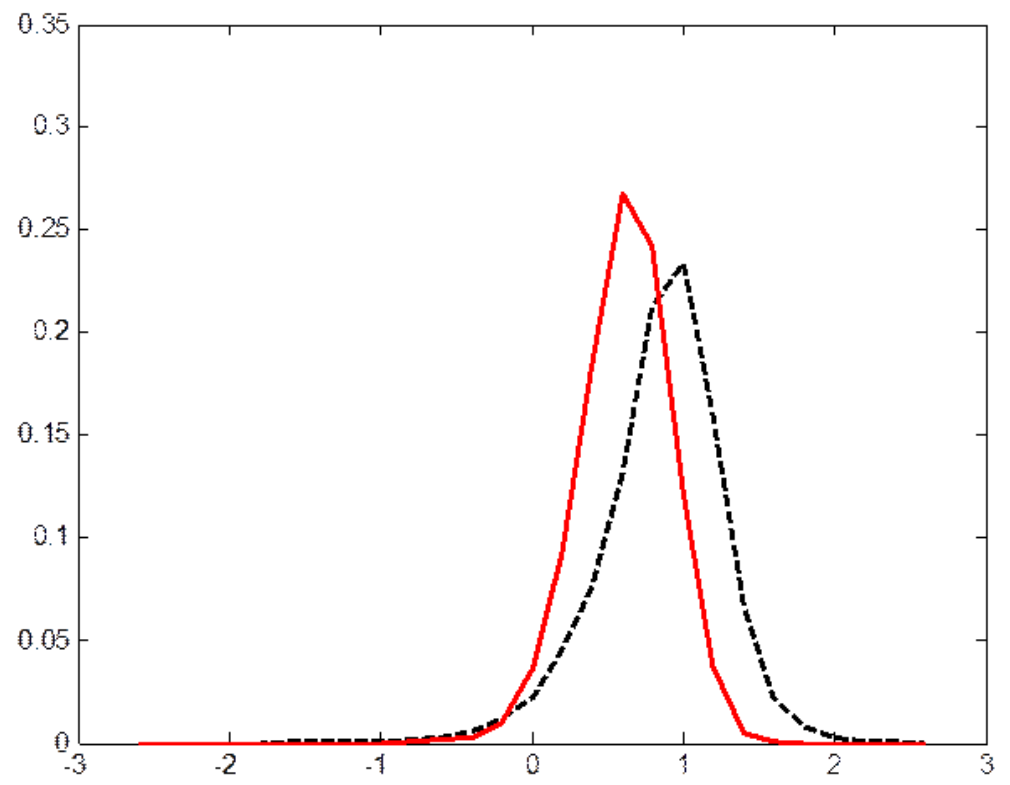

Note: the dotted line corresponds to complete information

Median slope

Complete information 0.8928

Incomplete information

Complete information

1.2966 0.6339

90-th quantile

th-quantile that corresponds to the unitary value

Complete information $63 \%$

Incomplete information $90 \%$ 
Figure 4. Density functions of simulated slopes. Sensitivity to parameter $\epsilon$ $(\epsilon=0.5)$

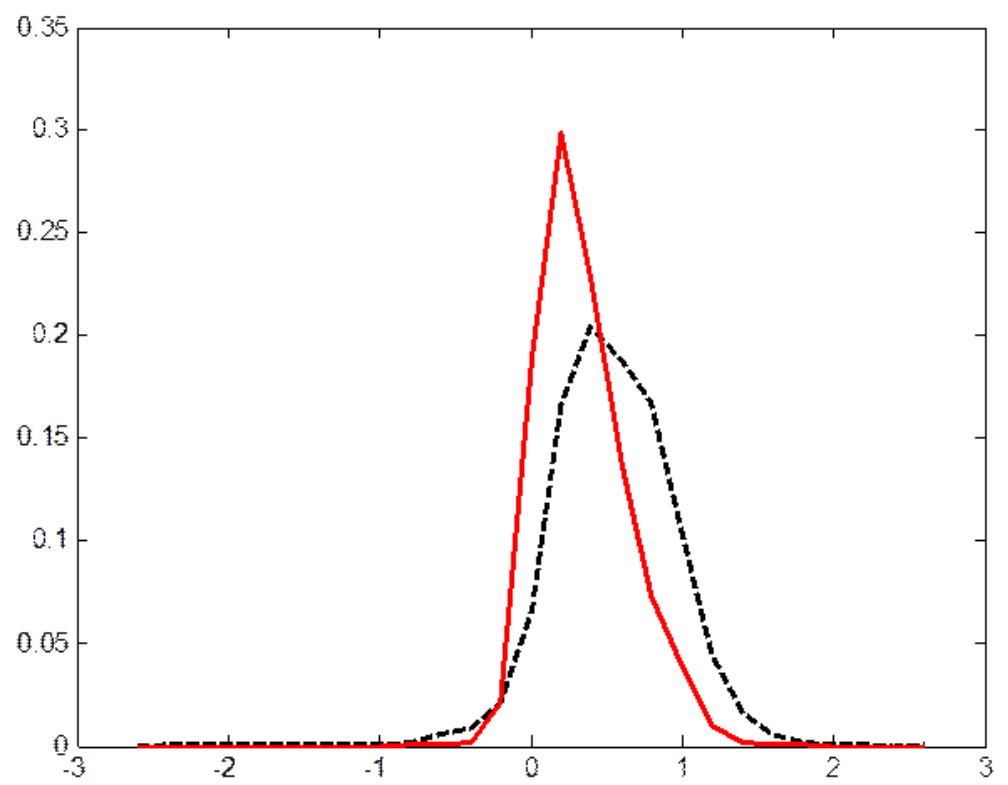

Note: the dotted line corresponds to complete information

Median slope

Complete information

0.5280

Incomplete information

Complete information 0.2928

90-th quantile

1.0225

Incomplete information

th-quantile that corresponds to the unitary value

Complete information $91 \%$

Incomplete information $98 \%$ 
Figure 5. Density functions of simulated slopes. New baseline parameterization

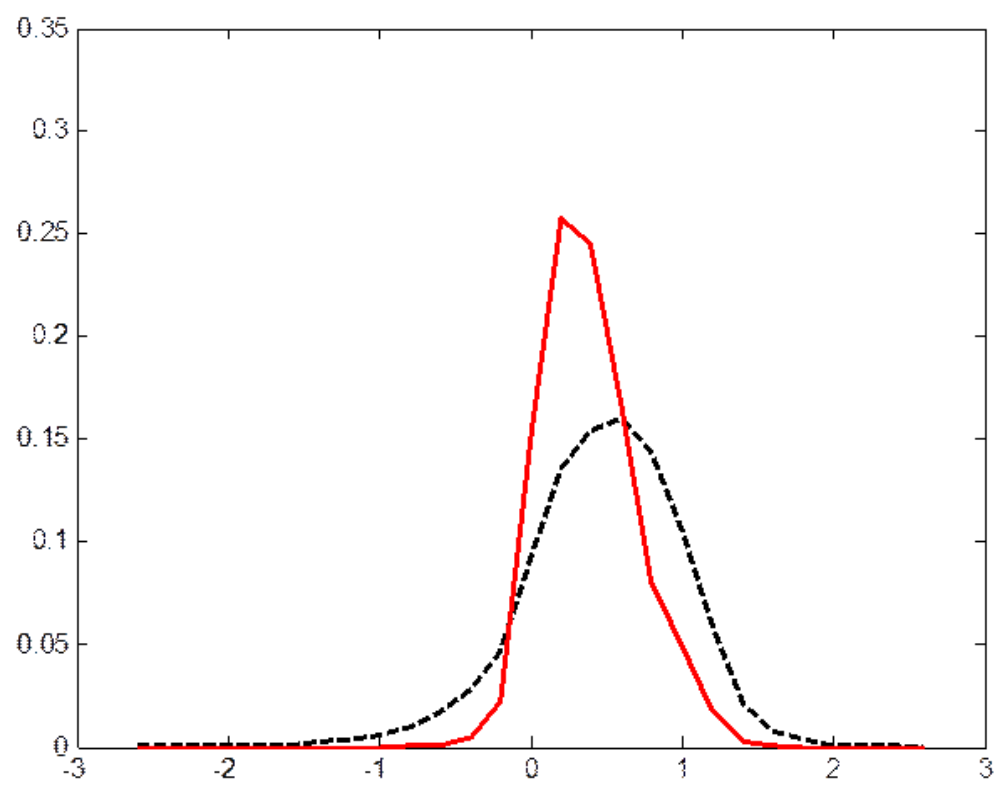

Note: the dotted line corresponds to complete information

Median slope

Complete information Incomplete information

0.5005 0.3458

Complete information

90-th quantile

th-quantile that corresponds to the unitary value

Complete information

$86 \%$

Incomplete information

$96 \%$ 